\title{
AN EMPIRICAL STUDY OF BRAND SWITCHING FOR A RETAIL SERVICE
}

\author{
Michael S. Morgan \\ Cornell University \\ School of Hotel Administration \\ 545 Statler Hall \\ Ithaca, NY 14853 \\ <INTERNET: msm6@comell.edu> \\ Chekitan S. Dev \\ Cornell University \\ School of Hotel Administration \\ 252 Statler Hall \\ Ithaca, NY 14853 \\ Cornell University
}

\begin{abstract}
The purpose of our study is to identify and measure the relative influence of different factors contributing to brand switching in a retail service context. We examine three types of variables related to brand switching for a high involvement, experience-oriented retail service: (1) changes in usage context or situation; (2) marketing mix variables which are directly controllable by the firm; and (3) customer background variables. Using data from an extensive survey of lodging customers, we build a model of the probability of brand switching as a function of these variables and implement three measures of relative variable influence. The strategic marketing implications of the findings are discussed.
\end{abstract}




\section{CUSTOMER BRAND SWITCHING}

A recent article on customer satisfaction measurement (Fornell 1992) points out that one of the firm's primary reasons for increasing customer satisfaction is to reduce the amount of switching to one's competitors. Levin (1993) notes, moreover, that retaining customers is a less costly and more efficient marketing strategy than finding new customers. An emphasis on retention has driven service companies_especially those with a high “experience” (cf Nelson 1974) component—such as lodging companies, restaurants, cruise ships, hair salons, etc.—- to concentrate on improving the satisfaction of existing customers. ${ }^{1}$

In many cases, a firm cannot attribute brand preferences entirely to customer satisfaction (or other responses under the firm's control). This is especially true in the retail service industry, where often the specific usage context is a critical determinant of such preferences—see, for example, Srivastava, Alpert and Shocker (1984), Miller and Ginter (1979) and Belk (1976). Moreover, beyond the influence of situation on brand preference (or preference within a context), it is important to note more specifically that changes in situations should be tied directly to changes in brand choice over time-that is, to switching among brands. In this study, we provide this additional perspective to the brand preference picture, especially in modelling influences on brand switching that may be somewhat beyond the control of either the firm or the individual buyer.

In addition to firm-controlled and context-specific influences, customer background characteristics may affect brand switching and repeat purchase behaviors directly. For example, higher income class customers can overcome lack of availability of their favorite brands and hence avoid “forced” switches by paying a price premium to steady or reliable suppliers. Other demographic measures may influence repeat choices as well (e.g., see Moutinho and Trimble 
1991, for repeat tourist destination choice). We argue here that the relative strength of these various influences needs to be examined in order for managers to develop appropriate customer retention strategies.

One specific retail service context—-the U.S. lodging stay ${ }^{2}$ market—is examined in this study. A key concern of managers of lodging enterprises, as in other retail service businesses, is to decrease customer loss due to brand switching. We first define relevant variables within three general types (which we call CONTEXT, CUSTOMER and CONTROL, defined below), drawn from an extensive survey data base on lodging customers. Then we incorporate these variables into a model of the probability of lodging brand switching and repeat purchase. Finally, we report the relative influence of the variables individually and by type.

The next section provides a review of some background literature. Following this is a description of how we operationalize lodging brand switching and repeat purchase, and give the definitions of the variables used in our model of switching. We develop our modelling application and measures of relative influence of the three general types of variables. We conclude with our overall summary and conclusions. We further interpret the results and discuss their strategic marketing implications in the Executive Summary.

\section{LITERATURE REVIEW}

Among prior studies of the covariates of brand switching are Carpenter and Lehmann (1985) and Hauser and Wisniewski (1982). These studies essentially model brand switching probabilities as a function of marketing mix actions for consumer packaged goods. We extend this approach to incorporate as well non-marketing mix variables related to usage context and 
customer characteristics in a model of brand switching in a high involvement retail service industry.

Typology of influences on brand switching behavior. We examine in this study three types of variables which can influence ${ }^{3}$ brand switching for this type of good: (1) changes in usage context or situation (which we call CONTEXT variables); (2) variables such as marketing mix actions which are more or less directly controllable by the firm (called CONTROL variables); and (3) heterogeneous customer variables such as demographics and other background characteristics (called CUSTOMER variables).

This typology is developed on the basis of others in empirical and theoretical work on retail market structures (Ingene and Brown 1987; see also Ingene and Lusch 1981, Bucklin 1972) in that the customer demographic characteristics, environment and marketing mix — which can be rephrased as CUSTOMER, CONTEXT and CONTROL variables, respectively_are viewed as joint influences on customer retail purchase behavior and competitive retail industry structure. The difference is that our CONTEXT variables include more specific situational and usage constraints and influences on buying behavior rather than the broad geographically-defined variables of these previous studies. The reason for this is that our application is to a market in which customers are much more geographically diffuse than in more localized retail markets.

The CONTEXT/CONTROL/CUSTOMER typology is also similar to Pessemier’s (1980) development of the major influences on retail patronage. In fact, Pessemier's suggested measure of "patron turnover” is similar to our empirical measure of customer brand switching. However, Pessemier defines "patron turnover” as the permanent loss of customers, while we are simply examining data reflecting two-purchase sequences. It is possible that our switching customers return to an originally chosen brand in a later, unobserved sequence. Thus, Pessemier grounds 
the notion of patron turnover in the concept of dissatisfaction, while we additionally examine a wide range of situational and context-specific influences on switching.

The behavioral model to which our CONTEXT/CONTROL/CUSTOMER typology most closely corresponds was developed by Bloch and Richins (1983) and Celsi and Olson (1978). They examine “consumer characteristics, product characteristics and situational context” as influences on the degree of involvement consumers feel with respect to a product class. Although we focus on switching behavior, there is, in principle, a relationship between switching and involvement since habitual, non-involving purchase situations tend to lead to unconscious repeat purchase behavior (Assael 1987). Hence, our CONTEXT/CON- TROL/CUSTOMER variables can also be thought of as perhaps influencing the level of involvement, variety seeking, cognitive processing and hence, brand switching behavior. The relationship between involvement and switching is not addressed here, however, and would require a substantially different research strategy to explore more fully. The theoretical framework we are using in our application to the lodging market, along with the variables which we identify (see next section) within each type, is illustrated in Figure 1.

\section{MEASURING CUSTOMER BRAND SWITCHING COVARIATES}

This study uses survey data collected in 1990 by a firm specializing in market research for the lodging industry. ${ }^{4}$ A survey questionnaire was mailed in successive monthly waves over a six-month period to members of the National Family Organization ombudsman panel. Data were obtained on all lodging stays purchased by respondents over the previous three-month period. Details ranging from transportation to purpose of travel were recorded, including room prices, deals, satisfaction ratings, destinations, etc. At the same time, demographics and other 
respondent background variables were incorporated from the NFO data base. Although limited to self-reported data, the resulting data base is rich in details about customer travel situations and lodging stays.

The limitation of self-reporting to the previous three-month period is believed to avoid an unreasonable strain on respondent memory. However, in order to provide the minimum amount of noise or bias from memory loss, we further restricted our attention to the most recent two stays reported by multiple-stay respondents. Switching and repeat purchase were then recorded on the basis of this restricted sample. Despite the restrictions, we were able to use 4,507 reported purchases from the original data base. Of the 4,507, 1,326 (29\%) were repeat brand purchases and 3,181 (71\%) were brand switches.

A potential selection bias in favor of heavier users exists because eligible respondents have bought lodging stays twice or more in the three month period. This potential is minimized by including stays reported during all three months of the summer season, when the bulk of individual travel occurs in the U.S., so that lighter users have a better chance of sample inclusion. Selection bias is also minimized by including only the most recent two stays for each customer, thus reducing the potential amount of representation in the data by heavy users with more than two stays. Although selection bias has been minimized in these ways, it is important to note that the potential for such bias still exists, and the generality of the results should be interpreted accordingly.

The limitation of the data to two-stay sequences prohibits using more elaborate measures of behavioral loyalty requiring longer purchase histories (cf Kumar, Ghosh and Tellis 1992). However, Bucklin and Srinivasan (1991), in a survey-based study of the coffee market, collect self-reported behavioral measures using an approach which is similar to ours. 


\section{VARIABLE DEFINITIONS}

Motivation. Most choice models rely on the notion that the chooser responds primarily to changes in his/her environment, or to differences among alternatives rather than to the absolute value of the features of the alternatives (Cooper and Nakanishi 1988). This should be even more the case when the "alternatives" to be chosen are to switch or not to switch from a previous brand. Such a perspective is also consistent with an adaptation-level response to the choice environment (Helson 1964). As a result, most of the variables we define to predict switching are expressed in terms of changes in the brands used from one consumption to another-changes in consumption situations or contexts, prices paid, etc.

Assumption of stationarity. Throughout the analysis, we assume that the effects on brand switching are stationary. This assumption implies that the preference structure of the customer does not change from one stay to another, so that differences among stay characteristics will reliably predict whether the second stay will be with a different brand than the first. For example, we see below that if customer satisfaction is higher on the second stay, a brand switch is predicted. This reflects a relative difference in customer satisfaction between the two chains rather than dissatisfaction with the first chain leading in time to a switch to the second chain. One can visualize, under stationarity, a "reverse time" process in which customers switch (or repeat purchase) backwards in time as well as forwards. An alternative conceptualization, not available with the data considered in this study, is to assume that the customer's preference structure is nonstationary. That is, the customer's responses to the same stimulus may change over time from stay to stay, as when buyers are learning about a new product. Given the maturity of the lodging market, however, stationarity is a more reasonable assumption. 
Variable selection and classification into types. We first reviewed a set of potentially influential variables in the survey data base. ${ }^{5}$ Where appropriate, we created new variables which reflect relative differences between current and prior stay characteristics. For example, a binary "increase/decrease in room price" variable is intended to capture the effects on switching of changes in relative price, as opposed to absolute price. Also, dummy variables reflecting changes in travel context and situation were created—for example, variables which reflect a change from "bringing (or not bringing) kids last time" to "not bringing (or bringing) kids this time".

We then grouped the variables according to the typology discussed in the literature review section. These variables (along with a description of how each was coded from the survey data), and their univariate statistics are shown in Table 1.

The CONTEXT variables are designed to measure the influences on switching due to changes in the situation or usage context of the lodging stay. This can be thought of as not directly controllable (in the short run) by the lodging firm, but which nevertheless have a strong impact on the traveller's choice of lodging accommodations. CCITY captures stay differences in the availability of lodging brands from city to city. Because of the predominant influence of location on spatial choice behavior (Bucklin 1972), we expect this variable to explain a large proportion of the variance in lodging brand switching. CWHO reflects differences in the purpose of the stay, since one normally pays for one's own room under certain stay circumstances but not others. This variable will capture to some extent the tendency of a customer to choose more or less expensive accommodations depending on whether he/she will be personally responsible for the charges.

CPAY reflects changes a buyer's ability to use one payment vehicle (e.g., company credit card) instead of another (e.g., one's own cash) and hence change the accessibility of different 
lodging brands. Like CWHO, it will reflect changes in circumstances surrounding the purpose of the trip. CTRAN is also a situational variable which also reflects changes in the geographic accessibility of different lodging brands (e.g., highway motels versus airport hotels). CPURP should influence switching to the extent that different lodging brands are more associated with different trip purposes. For example, there are more Travelodges in the resort areas of the Southwestern U.S. than in other types of areas. Hence, the Travelodge brand will be switched to more often when the purpose of travel changes from business to leisure.

CKIDS should impact switching to the extent that different lodging brands are more associated with family, as opposed to individual travel. For example, Hyatt promotes special programs for kids. CATOWN is a locational variable like CC1TY, except that it reflects changes in the type of town area rather than the city visited. It should capture the effect of availability of brands in the area of town destination.

Unlike the CONTEXT variables, the CONTROL variables can, in principle, be directly manipulated by the lodging firm in the sort run. Thus, they represent important decision variables for the firm in its ongoing marketing strategies. CDEAL (changes in whether or not the customer receives a special deal from one stay to another) reflects customer response to special deal offers. ISATIS reflects the response of the customer to relative increases in satisfaction. It should also be noted that this measure of changes in satisfaction represents the composite of underlying attributes, benefits and the cognitive integration process needed to produce a satisfaction judgment on each stay occasion. IPRICE (whether the room price paid increases from one lodging stay to another) impacts switching for the same reasons as does ISATIS. That is, switching is a response to a relative change in room price from one lodging stay to another. It should be noted that we have limited attention to only changes in deal status, and to only 
increases in price or satisfaction. The reason for this is that including variables which correspond to constant deal status or to decreases in price or satisfaction leads to collinearity effects on the model results. However, below we do additional checking of the omitted effects to insure that they are of the opposite sign from that for the included variables, which confirms our interpretation of the results. Also, we check some selected interaction effects (see Results section).

Another CONTROL variable is CLUB, which is designed to capture the customer's propensity to stay with a brand for which he or she can accumulate bonus points or other benefits of travel club membership. While CLUB is arguably a customer background variable rather than a marketing mix variable, we frame it as part of the marketing mix because it can be controlled by lodging firms through advertising and sales promotion tactics.

Unlike the CONTEXT variables, which measure situational influences on switching, and the CONTROL variables, which reflect the lodging firm's direct attempts to influence switching, the CUSTOMER variables capture the effects of customer background variables. FAM is a measure of brand familiarity, loyalty and, conversely, of variety seeking by the individual. ${ }^{6}$ Prior stay has been shown to be a very important determinant of customers' lodging brand beliefs and recall (Morgan 1991). INCOME should reflect the customer's relative ability to afford the lodging brands he or she prefers despite changes in city destination or other circumstances. All else being equal, the higher household income, the less switching is expected because customers can exercise their preferences independently of differences in situation or room prices across stays. BUS should reflect the customer's degree of experience with the product class. We include this variable because it has been shown in prior studies (e.g., Charlton and Ehrenbeig 1973) that 
the greater the number of trials, the more loyal to favorite brands the customer normally becomes. Thus, all else being equal, BUS should have a negative effect on switching.

\section{BINARY PROBIT MODEL-PARAMETER ESTIMATES AND RELATIVE EFFECTS}

A two-state probit model (see Amemiya 1981) of brand switching/repeat purchase probability was calibrated over the entire data set using the set of variables described in customer brand switching covariates section as predictors. ${ }^{7}$ The probit model used is:

$$
P(\text { switch brands } \mid X)=P(Z>0 \mid X)=\int_{-\Sigma \beta X}^{\infty} f(\varepsilon) d \varepsilon
$$

where: $\quad f()=\quad$ standard normal density

$\mathrm{Z}=\quad \Sigma \beta \mathrm{X}+\varepsilon, \varepsilon \sim$ i.i.d. $\mathrm{N}(0,1)$ and

$\mathrm{X}=\quad$ variables included in model

$\beta=\quad$ model parameters estimated through numerical

maximization of the likelihood function associated with $\mathrm{P}(\mathrm{Z}>0)$ and $\mathrm{P}(\mathrm{Z}<0)$.

The probit model parameter estimates, their $t$-values and significance levels are shown in Table 2. The predictor variables are arranged into three groups by variable type.

We checked for potential multicollinearity problems in the following way. First, we noted that the maximum intervariable correlation among the predictor variables is .55. This is between CPURP and CWHO, and is plausible because changes from business to leisure travel often involve a change in the sponsor of lodging charges for the trip. We note, however, that both variables have a significant effect in the model, and so collinearity between them has not substantively affected the results. Next, we checked the condition number for the predictor variable set, which is 6.16, well below most conventional “danger zones” (Belsley, Kuh and 
Welsch 1980). The variance proportions associated with each eigenvalue, with the exception of CPURP and CWHO, are well within .50. As a result of these checks, we were generally satisfied that multicollinearity has not substantively affected the parameter estimates.

Results. The parameter estimate values are significant at a level of $p<.02$ or better (as expected) and findings for the variables seem intuitively plausible.

Among the CONTEXT variables, CCITY appears to have a predominant positive influence on brand switching $(p<.001)$. As conjectured above, this probably relates to differences in lodging brand availability across geographic regions (cf Bucklin 1972). ${ }^{8}$ The other CONTEXT effects of CWHO, CTRAN, CPAY, CPURP, CKIDS and CATOWN also all have the expected significant, positive impact on brand switching. Thus, CONTEXT variables are an important influence when customers switch away from an existing lodging supplier.

Among the CONTROL variables, CDEAL appears to be the most influential on brand switching, although all of the other variables have a positive impact as well. As explained above, CDEAL indicates whether the customer changes from a deal purchase to a no deal purchase or vice versa. Including both change and no change variables produced multicollinearity among the predictors, so only CDEAL was used. However, as additional checks, we ran the model separately with a deal-to-deal variable and with a no deal-to-no deal variable. The results indicated that each of these no-change variables have a significantly negative effect on switching $(p<.02)$. Also, we ran the model separately with a deal-to-no deal and with a no deal-to-deal variable, and both of these have a significantly positive effect on switching $(p<.002)$. These additional checks thus confirm the basic information provided by the CDEAL effect.

The positive influence of room price increases, IPRICE is particularly intriguing. The direct interpretation of this effect is that—after taking all other influences, such as location, into 
account—whenever the customer switches, he or she generally ends up paying a higher price. As with CDEAL, a corresponding price decrease variable was omitted due to multicollinearity. However, as an additional check, we ran the model separately with the price decrease variable, and the effect was negative, although not significantly $(p<.21)$. Thus, the interpretation of the IPRICE effect is confirmed. ${ }^{9}$ We would conjecture three possible explanations for this effect.

One is that the customer actually wants to repeat purchase from a previously used chain as long as the room price does not increase from one stay to another (this can be inferred from the positive sign of the effect of price change on switching). If the room price for the same chain increases, however, then any inherent customer preference to stay with a more familiar alternative is diminished. Another explanation, perhaps related to the first, is that, when switching brands for any reason other than price, the customer actually tends to seek out a higher price alternative than that previously chosen, in effect paying a "risk premium” against quality uncertainty in the subsequent, less familiar chain. Finally, there is an explanation which parallels a type of "upward” attraction that higher priced, premium brands exhibit in consumer packaged goods markets (Allenby and Rossi 1991, Carpenter and Lehmann 1985). It has been shown that higher priced (and, presumably higher quality) brands more easily compete with (draw customers from) the lower price tiers than vice versa, when consumers switch among brands.

It should be noted that ISATIS has a strong influence on switching as well, confirming the conventional wisdom that customers who are less happy with a chosen brand on one occasion will switch to a competitor on the next. Also, travel club membership (CLUB) has its expected effect of retaining customers (i.e., reducing switching), as seen from the negative sign of its parameter estimate. 
FAM appears to be the most influential CUSTOMER variable, and it is negatively related to switching. This effect indicates that customers who, on the first stay of a two-stay sequence, are repeat purchasing, exhibit a degree of loyalty across the observed two-stay sequence as well. This indicates that at least part of the market contains customers who have an inherent amount of brand loyalty to lodging chains, which parallels findings of significant brand loyalty in almost all types of repeat purchase markets (e.g., Kamakura and Russell 1989).

INCOME is also negatively related to switching. This is compatible with the notion, discussed above, that, all else being equal, customers with more wealth can afford to repeat purchase familiar lodging brands which they like, despite limited availability and wide price variation. Likewise, the number of business-related stay nights (BUS) decreases switching (negative parameter sign), suggesting that repeat purchasing does tend to foster a significant degree of brand loyalty, as conjectured above. Thus, as expected, all of the CUSTOMER background variables are significant at $p<.02$ or better.

Predictive validity test. A holdout sample test was made of the model's predictive validity. We calibrated the model parameters on a randomly selected $75 \%$ calibration sample and then predicted brand switching for the remaining $25 \%$ holdout sample. The hit rate (based on predicting a switch for an observation with a calculated $\mathrm{Z}$ value greater than zero) was $78 \%$, which is significantly better than either the chance-conditional-on-assignment probability of 59\% or the prior probability of $71 \%$.

Additional measures of relative variable influence. We compared the relative influence of all variables, as well as by CONTEXT, CONTROL and CUSTOMER group, in three ways. First, we computed arc elasticities for each predictor. Then, we computed a measure called $\rho_{-\mathrm{j}}^{2}$ which is similar to the partial $\mathrm{R}^{2}$ used in linear regression models. Each of these measures allows 
us to assess the relative influence of individual predictors. Then, we computed $\mathrm{BIC}^{10}$ measures to compare the relative influence of the three variable groups. These measures are shown in Table 3.

Arc elasticity comparisons. Comparing predictor variable elasticities can be problematic when these variables are measured in different types of scales. However, since all of our predictor variables were measured as binary $(0,1)$ coded events, we can apply a standard elasticity measure to each variable as follows:

a. First, the variable was set to 1 for all observations and the values of $\mathrm{z}=\Sigma \beta \mathrm{X}$ and $\Phi(\mathrm{z})=\mathrm{P}($ switch$)$ for each observation were computed.

b. Then the variable was set to 0 for all observations and again the values of $\mathrm{z}$ and $\Phi(\mathrm{z})$ were computed.

c. The difference between the computed $\Phi(\mathrm{z})$ for a. and b. was then averaged across the sample, yielding a measure of the "percentage change in switching" as a function of a change in the underlying variable.

It can be seen in Table 3 that CCITY has the greatest influence among the CONTEXT variables on lodging brand switching, CDEAL has the greatest influence among the CONTROL variables, and FAM is most influential among the CUSTOMER variables. This, along with other elasticity measures shown, parallels the parameter estimate findings discussed above.

$\rho_{-j}^{2}$ comparisons (see McFadden 1974). This measure is computed for each variable as follows:

a. First, the variable $j$ was excluded from the equation, and the log likelihood $\left(\mathrm{LL}_{-\mathrm{j}}\right)$ of the resulting probit model was derived. 
b. Then, the measure $\rho_{-j}^{2}=\left(1-L L / L L_{-j}\right)$ was calculated, where $L L$ is the log likelihood of the model including the variable. This gives a measure of the incremental contribution of a variable after all other influences have been accounted for. In order to make these more comparable, their proportionate rather than absolute values are shown in Table 3 (that is, they sum to 1).

Again, CCITY among the CONTEXT variables, CDEAL among the CONTROL variables and FAM among the CUSTOMER variables appear to have the greatest influence on lodging brand switching. This and the measures of $\rho_{-\mathrm{j}}^{2}$ reported in Table 3 are compatible with the parameter estimate and elasticity findings above.

BIC comparisons. In order to compare the relative influence of variables by group, it is necessary to apply a general test of fit to submodels which include only the variables in each group. The BIC measure has found wide acceptance in the marketing analysis of consumer packaged good data bases (Bucklin and Gupta 1993). In essence, BIC is a measure of the log likelihood for the submodel penalized for the number of parameters used in the submodel and the sample size. The formula for submodel $i$ is $\mathrm{BIC}_{1}=-\mathrm{LL}_{1}+1 / 2 \mathrm{k}_{\mathrm{i}} \ln \mathrm{N}$, where $\mathrm{LL}_{1}$ is its $\log$ likelihood, $\mathrm{k}_{\mathrm{i}}$ is the number of parameters and $\mathrm{N}$ is the sample size. The objective is to "favor" the model with the minimum BIC measure.

It can be seen in Table 3 that the model with CONTEXT-only variables is favored over models with either CONTROL-only or CUSTOMER-only variables. Thus, those variables included in CONTEXT, as a group, most influence lodging brand switching. Also, by the BIC measure, the second most influential group is that containing the CONTROL variables, followed by the CUSTOMER group. The strategic implications of these relative group influences are discussed in our Executive Summary. 
Limitations and directions for future research. This study could be improved with access to more substantial data on customer purchase histories—hopefully actual purchase observations, which are not subject to potential recall loss. It would then be possible to look at longer strings of purchases, to perhaps incorporate contextual information such as the financial health of a business traveller's company or the weather during a vacation trip.

A related limitation is the general lack of evidence sufficient to test the directions of causality between switching and the covariates. For example, when the lodging customer switches from one brand to another, he/she is significantly more likely to pay a higher room price. This may be due to a desire to pay a "risk premium" for a less familiar brand when the first brand is unavailable. Similarly, the endogeneity/exogeneity of other covariates is open to question. Further information in this area could enhance the process of targeting and strategic planning of marketing actions.

Another limitation is in the potential, in this type of secondary data analysis, for unobserved (omitted) variable effects, which can be confounded with the parameter estimates for the included variables. An example is locational convenience. While CCITY and CATOWN may be useful proxies for this important factor in the customer's experience, they are by definition derivative and post hoc. Hopefully, as additional data become available, such idiosyncratic factors as locational convenience can be incorporated directly into the model. Another more idiosyncratic factor is the quality of specific hotels within each chain. It is known that there can be variation in quality from hotel to hotel, especially across geographic regions. With the data currently available, we have had to rely on such differences being randomized out over the sample. With more extensive data, such differences could be accounted for explicitly. 
Finally, we have isolated only the chosen lodging brand alternatives for each observation. There is no information on the competitive set faced by the decision maker and on how competitive marketing information may have influenced the brand choice at each stay. This should be considered a substantial limitation on inferring causality between the predictors and the dependent variable of switching. Instead, we view only correlates of switching in the model presented. A more complete identification of causal direction awaits further research.

It should also be noted that we have analyzed data for one retail service industry (lodging), and therefore have not considered whether the relative influences of CONTEXT, CONTROL and CUSTOMER variables might be different across product or service types. However, the present study does contribute to our understanding of these relationships in the context of a high involvement retail service, and it hopefully opens the door to analysis of more thorough investigations across a wider variety of retail industries.

\section{SUMMARY AND CONCLUSIONS}

In this study, we identified and measured the relative influence of different factors contributing to brand switching in a retail service context. We examine three type of variables related to brand switching: (1) changes in usage situation (CONTEXT); (2) marketing mix variables (CONTROL); and (3) customer background variables (CUSTOMER).

We find that within the CONTEXT group of variables, CCITY is most influential on brand switching. We argue that this most likely reflects differences in lodging brand availability across geographic regions.

Among the CONTROL variables, CDEAL is the most influential, suggesting that, among marketing tactics, brand switching is most sensitive to the offer (or withdrawal) of a special deal. 
In addition to deal effects, room price changes have an interesting implication. When switching, customers tend to pay higher room prices, and we offer explanations for this based on preferences to stay with a chain if the price does not increase, a risk premium for uncertain quality when switching to a less familiar chain, and/or an attraction effect of higher quality brands which has been well documented for other industries. Which of these influences explains the price change effect is the subject of further empirical research.

Among the CUSTOMER variables, FAM is the most influential (and negative) effect on brand switching. We argue that this indicates that some customers-at least those for whom the previous stay in a two-stay sequence was a repeat purchase-have a degree of brand loyalty which is reflected in less switching across the observed two-purchase sequence.

The relative influence of each group can also be examined. We find that CONTEXT variables are most influential, followed by CONTROL and CUSTOMER variables. We suggest that the main reason CONTEXT variables have such a strong influence on switching in this industry (and perhaps in retail service markets in general) is that the customer cannot measure the total value of the experience independent of a specific consumption situation.

This suggests that marketing strategy for this type of retail service should be primarily context-based. Examples include special promotions for honeymoon packages and family reunion packages. Also, it is important for the service provider to help offset customers’ situational costs-e.g., by providing transportation to major attractions. Since the value of consumption depends on all events, constraints, surprises, etc., which occur during consumption, the intrinsic value of the good itself will depend on many ostensibly "extraneous" factors which marketing management should always take into account. 


\section{ACKNOWLEDGEMENT}

The authors would like to thank Jim Brown, Pradeep Chintagunta, the participants at the 1992 TIMS Special Interest Conference on Services Marketing and three anonymous JR reviewers for their helpful insights. Funding from the Cornell School of Hotel Administration Faculty Research Fund is gratefully acknowledged. Thanks also to Stowe Shoemaker for assisting with the data formatting and analysis. 


\section{Notes}

1. Conventional wisdom has it that the average American company loses $10 \%$ to $30 \%$ of its customers every year primarily because of dissatisfaction with the quality of the company's service (Reichheld 1990) In a related article on quality m service businesses, Reichheld and Sasser (1990) emphasize the importance of ‘zero defections’ as a critical business success factor. They estimate that companies can boost profits by almost $100 \%$ by retaining $5 \%$ of customers they would otherwise have lost

2. For the purposes of this study, a lodging "stay” is defined as an uninterrupted visit of one or more days in the same hotel, motel or other provider of paid overnight accommodations.

3. We are interested in causality, but the data are somewhat imperfect for inferring causality. This is partly because they are cross-sectional rather than time-series and partly because the intricacies of the possible cause-and-effect interactions are beyond the scope of the work presented here. Hence, by "influence", we also mean concomitant variation for which the direction of causality is not necessarily established.

4. The firm is D K. Shifflett and Associates. Information on how to obtain this type of data easily is available from the authors, as is the data base used in this particular study.

5. 5 A stepwise discriminant analysis (in which the dependent variable was switching from one choice occasion to another) was used to help winnow down the potential variable set from over 130 to about 30 Then, we used background knowledge about the product class (lodging) and theoretical conjecture to construct the final predictor set.

6. Although each stay is characterized in the data set in terms of whether the customer had "stayed with the chain before" (at some prior tune), it is not possible to use this information about the second stay of a two-stay sequence, as a predictor variable for switching, since it 
has an "accounting relationship" with the dependent variable. That is, if the customer has stayed with the same brand on the previous stay, he has by definition "stayed with the brand before ”

7. This approach is comparable to the binary discriminant analysis in LaBarbera and Mazursky (1983). However, they do not consider the relative contributions of different variable types to the probability of switching

8. In support of an availability explanation, we also found that the CCITY effect is largely attenuated when the model is run on data solely revolving stays with the top ten market share brands (13\% of all stays).

9. If a change in who pays for the accommodations results in switching to a lower price brand, then there may be an interaction effect between C WHO and IPRICE (or its counterpart price-decrease variable). Similarly, if a change in the purpose of travel results in a switch to a lower price brand, then there may be an interaction between CPURP and IPRICE (or its counterpart) However, in checking this we found no interactions significant at $p<15$.

10. Bayesian Information Criterion (Schwarz 1978) 


\section{REFERENCES}

Allenby, Greg M. and Peter E. Rossi (1991). “Quality Perceptions and Asymmetric Switching Between Brands.” Marketing Science, 10(3): 185-204.

Amemiya, Takehi (1981). “Qualitative Response Models: A Survey.” Journal of Economic Literature, 19. 1483-1536.

Assael, Henry (1987). Consumer Behavior and Marketing Action, Chpt 3. Boston: PWS-KENT.

Belk, Russell W. (1976). "Situational Variables and Consumer Behavior.” Journal of Consumer Research, 13: 157-164.

Belsley, D. A., E. Kuh and R. E. Welsch (1980). Regression Diagnostics, Identifying Influential Data and Sources of Collinearity, Chpt. 3. New York: Wiley.

Bloch, Peter H. and Marsha L Richins (1983). “A Theoretical Model for the Study of Product Importance Perceptions.” Journal of Marketing, 47: 69-81.

Bucklin, L. (1972). Competition and Evolution in the Distributive Trades, Englewood Cliffs, NJPrentice Hall.

Bucklin, Randolph E. and Sunil Gupta (1993). "Brand Choice, Purchase Incidence and Segmentation: An Integrated Approach.” Journal of Marketing Research, 29(2): 201-215.

Bucklin, Randolph E. and V Srinivasan (1991). "Determining Interbrand Substitutability through Survey Measurement of Consumer Preference Structures.” Journal of Marketing Research, 28: 58-71.

Carpenter, Gregory S. and Donald R. Lehmann (1985). “A Model of Marketing Mix, Brand Switching and Competition.” Journal of Marketing Research, 22: 318-329.

Celsi, Richard L. and Jerry C Olson (1978). “The Role of Involvement in Attention and Comprehension Processes.” Journal of Consumer Research, 15: 210-224. 
Charlton, P and A.S.C. Ehrenberg (1973). “McConnell’s Experimental Brand Choice Data.” Journal of Marketing Research, 10: 302-307.

Cooper, Lee G. and Masao Nakanishi (1988) Market-share Analysis: Evaluating Competitive Marketing Effectiveness. Boston: Kluwer.

Dumas, Rene Babish (1992). “New Price Strategies Evolve From Industry Distress.” Business Travel News, (September 28). 16.

Fornell, Claes (1992). “A National Customer Satisfaction Barometer: The Swedish Experience” Journal of Marketing, 56: 6-21.

Hauser, John R. and Kenneth J. Wisniewski (1982). “Dynamic Analysis of Consumer Response to Marketing Strategies.” Management Science, 28(5): 455-486.

Helson, Harry (1964) Adaptation-Level Theory. New York: Harper \& Row.

Ingene, Charles A. and James R. Brown (1987). “The Structure of Gasoline Retailing” Journal of Retailing, 63(4): 365-392.

Ingene, Charles A. and Robert F. Lusch (1981). “A Model of Retail Structure.” Research in Marketing, 5:101-164.

Kamakura, Wagner A and Gary J Russell (1989). “A Probabilistic Choice Model for Market Segmentation and Elasticity Structure.” Journal of Marketing Research, 26: 379-390.

Kumar, V., Amit Ghosh and Gerard J. Tellis (1992). “A Decomposition of Repeat Buying.” Marketing Letters, 3(4): 407-417.

LaBarbera, Pricilla and David Mazursky (1983). “A Longitudinal Assessment of Consumer Satisfaction/Dissatisfaction: The Dynamic Aspect of the Cognitive Process” Journal of Marketing Research, 20(4): 393-404

Levin, Gary (1993). “Marketers Flock to Loyalty Offers.” Advertising Age, May 24: 12. 
McFadden, Daniel F. (1974). “Conditional Logit Analysis of Qualitative Choice Behavior.” Pp. 105-142 in Frontiers in Econometrics, P. Zarembka (ed.). New York: Academic Press Miller, Kenneth E. and James L. Ginter (1979). “An Investigation of Situational Variation in Brand Choice Behavior and Attitude.” Journal of Marketing Research, 16: 111-123. Morgan, Michael S. (1991). “Traveler’s Choice: The Effects of Advertising and Prior Stay.” Cornell HRA Quarterly, (August): 15-26.

Moutinho, Luiz and John Trimble (1991). “A Probability of Revisitation Model. The Case of Winter Visits to the Grand Canyon.” The Service Industries Journal, 11(4)' 439-457.

Nelson, Phillip (1974). “The Economic Value of Advertising.” In Advertising and Society, Yale Brozen (ed.). New York: NYU Press.

O’Brien, Bridget (1992). “AMR’s Airline-Industry Fare Structure Heads for That Big Hangar in the Sky.” The Wall Street Journal, (October 9): Bl.

Pessemier, Edgar A (1980). Retail Patronage Behavior, Report No. 80-112, Marketing Science Institute, Cambridge, MA.

Reichheld, Frederick F. (1990). “Making Sure Customers Come Back for More.” The Wall Street Journal, (March 12): A10.

Reichheld, Frederick F. and W Earl Sasser, Jr. (1990). “Zero Defections: Quality Comes to Services.” Harvard Business Review, (September-October): 105-111.

Schwarz, Gideon (1978). "Estimating the Dimension of a Model.” The Annals of Statistics, 6(2): 461-464.

Sheth, Jagdish N (1983). “Emerging Trends for the Retailing Industry” Journal of Retailing, 59(3): 6-18. 
Srivastava, Rajendra K,, Mark I. Alpert and Allan D. Shocker (1984). “A Customer-oriented Approach for Determining Market Structures.” Journal of Marketing, 48 32-45. 
Table 1. Dependent and Predictor Variable Used in Study.

\begin{tabular}{|c|c|c|c|}
\hline Varıable: & Coding: & Mean & S.D. \\
\hline \multicolumn{4}{|c|}{ Dependent variable: } \\
\hline SWI & $\begin{array}{l}0 \text { (1) if same (different) lodgıng brand used on } \\
\text { both current and last stay }\end{array}$ & 071 & 0.46 \\
\hline \multicolumn{4}{|c|}{$\begin{array}{l}\text { Varıables used as predictors/correlates of lodging brand switching. } \\
\text { CONTEXT variables }\end{array}$} \\
\hline CCITY & $\begin{array}{l}0(1) \text { if same (different) city on both current and } \\
\text { last stay }\end{array}$ & 0.84 & 0.37 \\
\hline CWHO & $\begin{array}{l}0(1) \text { if same (different) person paying as on last } \\
\text { stay }\end{array}$ & 0.19 & 0.39 \\
\hline CPAY & $\begin{array}{l}0 \text { (1) if same (different) method of payment as } \\
\text { on last stay }\end{array}$ & 0.22 & 0.41 \\
\hline CTRAN & $\begin{array}{l}0 \text { (1) if same (different) mode of transportation } \\
\text { as on last stay }\end{array}$ & 0.28 & 0.45 \\
\hline CPURP & $\begin{array}{l}0 \text { (1) if purpose of travel (leisure/busıness) does } \\
\text { not (does) change }\end{array}$ & 018 & 045 \\
\hline CKIDS & $\begin{array}{l}0 \text { if kids brought both stays or on neither of the } \\
\text { stays, } 1 \text { otherwise }\end{array}$ & 0.12 & 0.32 \\
\hline CATOWN & $\begin{array}{l}0 \text { if same (different) area of town (downtown, } \\
\text { suburb, etc.) on current and last stays }\end{array}$ & 070 & 0.46 \\
\hline \multicolumn{4}{|c|}{ CONTROL varlables } \\
\hline CDEAL & $\begin{array}{l}0 \text { if recerved special deal on both stays, or on } \\
\text { netther stay, } 1 \text { otherwise }\end{array}$ & 0.15 & 0.36 \\
\hline ISATIS & $\begin{array}{l}1 \text { if etther overall satisfaction or price-value } \\
\text { satisfaction increased on the second stay, } 0 \\
\text { otherwise }\end{array}$ & 030 & 0.46 \\
\hline IPRICE & $\begin{array}{l}1 \text { if there was an increase in room price on the } \\
\text { second stay, } 0 \text { otherwise }\end{array}$ & 0.28 & 0.46 \\
\hline CCLUB & $\begin{array}{l}0 \text { (1) if customer belongs (does not belong) to } \\
\text { one of several frequent guest clubs }\end{array}$ & 0.54 & 050 \\
\hline \multicolumn{4}{|c|}{ CUSTOMER varıables } \\
\hline FAM & $\begin{array}{l}0 \text { (1) if customer reported (did not report) an } \\
\text { earlier stay with the same chain as that used on } \\
\text { the first stay of the two-stay sequence }\end{array}$ & 0.30 & 0.46 \\
\hline INCOME & $\begin{array}{l}0 \text { if household income is at/below the sample } \\
\text { median, } 1 \text { otherwise }\end{array}$ & 045 & 0.50 \\
\hline BUS & $\begin{array}{l}0 \text { if number of annual business trips is at/below } \\
\text { the sample median, } 1 \text { otherwise }\end{array}$ & 0.50 & 050 \\
\hline
\end{tabular}


Table 2. Model Parameter Estimates.

\begin{tabular}{llcccc}
\hline Variable type: & Variable name & Parameter. & stderr & $t$ & $p$ \\
\hline CONTEXT: & CCITY & 055 & 005 & 1144 & 0.01 \\
& CWHO & 0.51 & 0.08 & 6.49 & 001 \\
& CPAY & 0.52 & 0.06 & 8.09 & 0.01 \\
& CTRAN & 0.21 & 0.05 & 3.95 & 0.01 \\
& CPURP & 021 & 0.08 & 259 & 001 \\
& CKIDS & 0.21 & 008 & 2.80 & 001 \\
& CATOWN & 019 & 0.05 & 416 & 001 \\
CONTROL. & CDEAL & 048 & 0.08 & 622 & 001 \\
& ISATIS & 015 & 005 & 2.98 & 001 \\
& IPRICE & 021 & 0.05 & 4.15 & 0.01 \\
& CLUB & -0.16 & 004 & -3.79 & 0.01 \\
CUSTOMER: & FAM & -0.41 & 005 & -871 & 0.01 \\
& INC & -0.11 & 0.05 & -2.37 & 0.02 \\
& BUS & -017 & 0.04 & -389 & 0.01 \\
& model log likelihood $=$ & -2184.2 & & \\
\hline
\end{tabular}


Table 3. Arc Elasticities, Rho-j Squared, and BIC Comparisons.

\begin{tabular}{llccc}
\hline Variable type: & Variable name: & Arc Elasticity: & $\rho_{-j}^{2}$ & BIC \\
\hline CONTEXT: & CCITY & 0.171 & 0.275 & \\
& CWHO & 0.127 & 0.095 & \\
& CPAY & 0.132 & 0.147 & \\
& CTRAN & 0078 & 0.034 & \\
& CPURP & 0.055 & 0.015 & \\
& CKIDS & 0056 & 0.017 & 2330.5 \\
CONTROL. & CATOWN & 0053 & 0.037 & \\
& CDEAL & 0.119 & 0.089 & \\
& ISATIS & 0041 & 0019 & \\
& IPRICE & 0057 & 0.037 & \\
CUSTOMER: & CLUB & -0.030 & 0.031 & \\
& FAM & -0.118 & 0.161 & \\
& INC & -0.045 & 0.012 & \\
& BUS & -0.048 & 0.032 & 2901.7 \\
\hline
\end{tabular}




\section{CONTEXT}

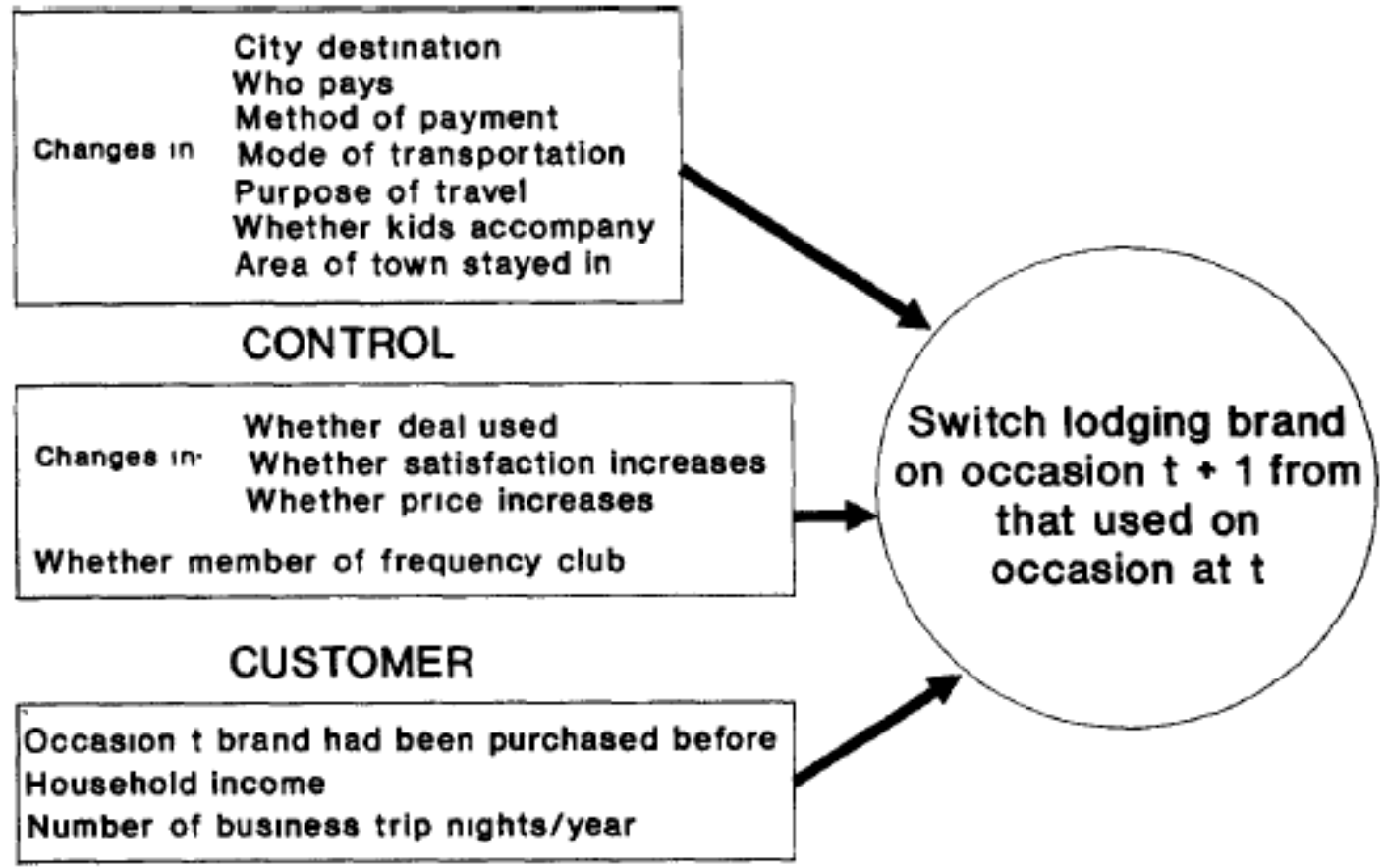

Figure1. Conceptual Framework to Describe Lodging Brand Switching 